\title{
Correction to: A new and effective method for human retina optic disc segmentation with fuzzy clustering method based on active contour model
}

\author{
Ahmad S. Abdullah ${ }^{1,2}$ • Javad Rahebi ${ }^{3}$ (D) Yasa Ekşioğlu Özok ${ }^{1} \cdot$ Mohanad Aljanabi $^{1,4}$
}

Published online: 2 December 2019

(C) International Federation for Medical and Biological Engineering 2019

\section{Correction to: Med Biol Eng Comput https://doi.org/10.1007/s11517-019-02032-8}

Following publication of the original article [1], the authors noted a typesetting mistake in the placement and numbering of equations (1) to (8).

The following paragraph in section 2.1.1 Pre-processing has been corrected by placing the first equation in the correct place. 'In the median filter, the pixel value is selected by taking the middle section of the pixels. The median filter for the pixels $(\mathrm{x}, \mathrm{y})$ value means all the pixels will change to the median value of the neighborhood as in Eq. (1) [10].'

$f_{\text {med }}(x, y)=$ median $\{f(s, t)\},(s, t) \in W_{x y}$
Equation one in the section 2.1.3 Active contour model has been corrected and replaced with equation (2). Equation (2) is as follows:

$$
\begin{gathered}
c(i)=[x(i), y(i)] \\
i \in[0,1]
\end{gathered}
$$

The numbering sequence of subsequent equations (3) to (8) has also been revised and the original article corrected.

\section{References}

1. Abdullah AS, Rahebi J, Özok YE et al (2019) Med Biol Eng Comput. https://doi.org/10.1007/s11517-019-02032-8

The online version of the original article can be found at https://doi.org/ 10.1007/s11517-019-02032-8

Ahmad S. Abdullah

Ahmed.alogaidi28@gmail.com

Javad Rahebi

jrahebi@thk.edu.tr

Yasa Ekșioğlu Özok

yasa.eksioglu@altinbas.edu.tr

Mohanad Aljanabi

mohanad.aljanabi@ogr.altinbas.edu.tr

1 Altinbas University, Istanbul, Turkey

2 University of Diyala, Baqubah, Diyala, Iraq

3 University of Turkish Aeronautical Association, Ankara, Turkey

4 Al-Furat Al-Awsat Technical University, Kufa, Iraq 